\title{
Gas-Phase Advanced Oxidation (GPAO) for Gas Containing Benzene Series by Ultraviolet Irradiation/Hydrogen Peroxide Vapour (UV/[H2O2]g) Process
}

\section{Yuping Jiang ( jyp@zsc.edu.cn )}

University of Electronic Science and Technology of China Zhongshan Institute https://orcid.org/00000003-2538-973X

\section{Juanjuan SONG}

University of Electronic Science and Technology of China Zhongshan Institute

Andong Zhu

University of Electronic Science and Technology of China Zhongshan Institute

\section{Research Article}

Keywords: Hydrogen Peroxide Vapour, Benzene series, Degradation, Conductivity, Characteristic absorbance

Posted Date: April 14th, 2021

DOl: https://doi.org/10.21203/rs.3.rs-218136/v1

License: (c) (1) This work is licensed under a Creative Commons Attribution 4.0 International License. Read Full License

Version of Record: A version of this preprint was published at Environmental Science and Pollution Research on October 14th, 2021. See the published version at https://doi.org/10.1007/s11356-02116920-w. 
1 Gas-Phase Advanced Oxidation (GPAO) for Gas Containing

2 Benzene Series by Ultraviolet Irradiation/Hydrogen Peroxide Vapour

$3 \quad\left(\mathrm{UV} /\left[\mathrm{H}_{2} \mathrm{O}_{2}\right]_{\mathrm{g}}\right)$ Process

\section{Yuping JIANG, Juanjuan SONG, Andong ZHU}

(University of Electronic Science and Technology of China, Zhongshan Institute, Zhongshan City, 528400, Guangdong Province, China)

\section{ABSTRACT}

Hydrogen peroxide $\left(\mathrm{H}_{2} \mathrm{O}_{2}\right)$ has the remarkable characteristics of strong oxidation, in which its vapour $\left(\left[\mathrm{H}_{2} \mathrm{O}_{2}\right]_{\mathrm{g}}\right)$ has further advantages, such as economize and good light transmission. But there is very rare research about its degradation effect in Gas-Phase Advanced Oxidation (GPAO). In the present study, the photochemical oxidation for gas containing benzene series, using ultraviolet (UV) irradiation and $\left[\mathrm{H}_{2} \mathrm{O}_{2}\right]_{\mathrm{g}}$, was investigated in a transparent bag made of fluorinated ethylene propylene (FEP). Only UV or $\left[\mathrm{H}_{2} \mathrm{O}_{2}\right]_{\mathrm{g}}$ hardly reduced the pollutant in 5 hours in which the reactor was also stable. With the high pollutant concentration (248 to $756 \mathrm{mg} / \mathrm{m}^{3}$ ) and short residence time (3S) compared with the related studies, studying the degradation of benzene, toluene and xylene, the apparent rate by $\mathrm{UV} /\left[\mathrm{H}_{2} \mathrm{O}_{2}\right]_{\mathrm{g}} /($ powder active carbon, PAC) was higher compared with 
the different way $\left(\mathrm{UV} /\left[\mathrm{H}_{2} \mathrm{O}_{2}\right]_{\mathrm{g}}, \quad \mathrm{UV} /\left[\mathrm{H}_{2} \mathrm{O}_{2}\right]_{\mathrm{g}} / \mathrm{TiO}_{2}\right.$ and $\left.\mathrm{UV} /\left[\mathrm{H}_{2} \mathrm{O}_{2}\right]_{\mathrm{g}} / \mathrm{ZnO}\right)$, but it was found that the terminal degradation by

$\mathrm{UV} /\left[\mathrm{H}_{2} \mathrm{O}_{2}\right]_{\mathrm{g}}$ significantly decreased, in which the conductivity decreased after reaction. The effects of increasing pollutant concentration and $\mathrm{H}_{2} \mathrm{O}_{2} \mathrm{pH}$ were negative for the treament, but the UV radiated power positive till $40 \mathrm{~W}$. In addition, the characteristic absorbance for three benzene series showed that the key structure of pollutant molecule were damaged in GPAO.

\section{Key word:}

Hydrogen Peroxide Vapour; Benzene series; Degradation; Conductivity; Characteristic absorbance

\section{Introduction}

People need to breathe every time, so everyone can not avoid the influence of the pollution. But as widely known in reality, air quality is not too well, specially in development countries. Thus the removal ways are increasingly studied, in which the removal methods of air pollution include adsorption, absorbtion, advanced oxidation (AO) and so on. Compared with other treament ways, AO shows more complete and quicker removal of pollutants, in which 
photochemical methods (without catalyst) have obtaining more attention in recent years [Alapi et al., 2007; Jinhan et al., 2009; Lianfeng et al., 2013], because there are some distinctive advantages, such as energy efficiency and running costs which must be evaluated in reality [Matthew et al., 2014].

Both hydrogen peroxide and ozone are the well known oxidants, are usually used in aqueous and gas systems respectively [Wang et al., 2000]. Although ozone is probably the oxidant leader-species becauseits $2.07 \mathrm{~V}$ oxidation-reduction potential (ORP) is higher than hydrogen peroxide $1.8 \mathrm{~V}$, the two substances have the same effect that can produce the $\mathrm{OH}$ radical regarded as the key oxidant in $\mathrm{AO}$ process. Further more, $\mathrm{H}_{2} \mathrm{O}_{2}$ has multiple features. First, it is very easy to generate the substance as long as electron donators exist in the water, chromophoric substances can produce hydrated electrons by illumination and combine with dissolved oxygen, which leads to a series of reactions for $\mathrm{H}_{2} \mathrm{O}_{2}$ outcome [Anastasio et al., 1997; Wohlgemuth et al., 2001]. Second, the artificial production for hydrogen peroxide is very convenient, even for the in-situ production[Choudhary and Jana, 2007;Fang et al., 2013]. Third, $\mathrm{H}_{2} \mathrm{O}_{2}$ can be used as an indicator of $\mathrm{AO}$ process, because the representative oxidant, hydroxyl radical $(\mathrm{OH}$.) with $2.8 \mathrm{~V}$ ORP, can be led to $\mathrm{H}_{2} \mathrm{O}_{2}$ formation by reacting with VOCs, $\mathrm{CO}, \mathrm{SO}_{2}$ and so on. 
It is obvious that in the $\mathrm{AO}$ with multiple reaction by radical chains, hydrogen peroxide plays the central role [Detlev et al., 2009].

Due to the uniqueness for $\mathrm{H}_{2} \mathrm{O}_{2}$, the $\mathrm{AO}$ by $\mathrm{H}_{2} \mathrm{O}_{2}$ was usually used as oxidatant solution to remove liquid pollutants, combined with ultraviolet radiation(UV) [Bin et al., 2007; Muruganandham et al. 2004], in which the solution state of reactants caused the long residence time for the waste. To the gas pollutants treatment, some researchs displaied that the $\mathrm{UV} / \mathrm{H}_{2} \mathrm{O}_{2}$ could oxidize $\mathrm{SO}_{2}, \mathrm{NOx}$ and $\mathrm{Hg}^{0}$ with low concentration in flue gas[Yangxian et al., 2011; Yangxian et al., 2014]. However, the researchs focusing on GPAO by $\left[\mathrm{H}_{2} \mathrm{O}_{2}\right] \mathrm{g}$ were very rare, especilly with the high pollutant concentration and short residence time, even if the vapour was only used for sterilization [French et al., 2004; Xue et al., 2012]. Actually, the vapour form for $\mathrm{H}_{2} \mathrm{O}_{2}$ not only maintain the features of solution-phase, but also cause some advantage, such as saving oxidant consumption and reducing the loss of UV light when passing the reaction system.

To research the GPAO by $\mathrm{H}_{2} \mathrm{O}_{2}$ vapour, and understand the effect for the harsh condition compared with the related studies, such as high concentration pollution and short residence time. We conducted the experiment to investigate the decomposition of benzene, toluene and xylene by $\mathrm{UV} /\left[\mathrm{H}_{2} \mathrm{O}_{2}\right]_{\mathrm{g}}$, the reactions took place 
in the transparent bag of fluorinated ethylene propylene (FEP) .

Benzene series were chosen as the target compounds because they were the frequently encountered organic pollutants including benzene, toluene and xylene, for example benzene and toluene is the frequently encountered organic compounds in indoor and outdoor environments [Wallace et al., 1985; Bernstein et al., 2008], serve as the representative organic contaminant [Liu et al., 2016], can cause the multiple diseases for people.

\section{Experimental section}

\subsection{Materials and analysis}

The reagents were used as received without further treatment. Benzene, toluene, xylene, $\mathrm{Na}(\mathrm{OH}), \mathrm{HCl}$ and $30 \%$ commercial $\mathrm{H}_{2} \mathrm{O}_{2}$ solution (Guoyao chemical Reagent Co., China), were analytical reagents (AR). 


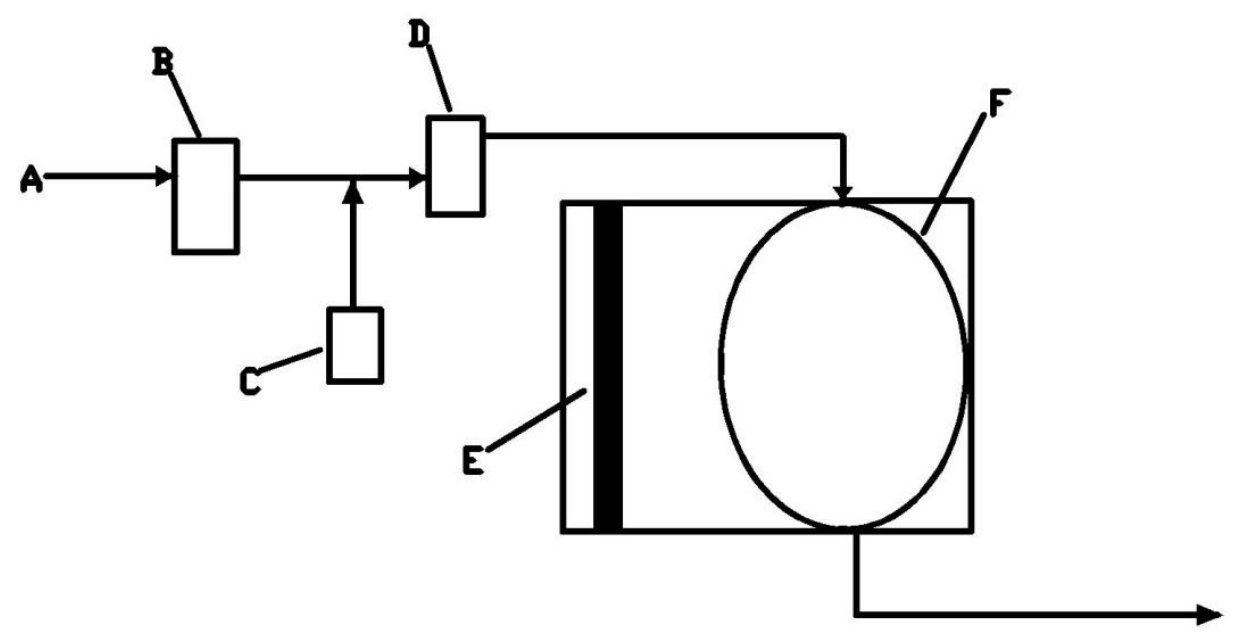

Fig. 1.Schematic of experimental system. Legend: A, Air; B, liquid 103 pollutant vessel; $\mathrm{C}, \mathrm{H}_{2} \mathrm{O}_{2}$ solution vessel; $\mathrm{D}$, gas mixing tank; $\mathrm{E}$, UV 104 lamp (253.7nm); F, FEP bag.

The experimental system used in this study was illustrated in 107 Fig. 1. The flows of air was blown through the FEP pipes and 108 regulated by the rotameters, to transfer and mix the vapour of 109 benzene series and $\mathrm{H}_{2} \mathrm{O}_{2}$. According to the requirement, powder 110 active carbon (PAC), $\mathrm{TiO}_{2}$ and $\mathrm{ZnO}$ of the equal quality (2g) were 111 put into gas mixing tank. Then the mixed gas photo-reacted in the 112 FEP bag under the UV lamp irradiation. The inlet and outlet 113 concentrations of reactants were measured through the gas bypass 114 line. To determined the apparent degradation rate, the pollutant 115 concentrations were monitored via gas chromatography (GC) with 
FID and AB-INOWAX fused silica capillary column in which the

117 retention time was $1.2-1.6 \mathrm{~min}$ and calculated by equation (1); to

118 terminal rate, vis $\mathrm{CO}_{2}$ detector (GT-1000- $\mathrm{CO}_{2}$, made in KORNO Co.

119 Ltd. China). The characteristic absorbance for pollutant was

120 determined by UV-vis spectra. The apparent and terminal removal

121 efficiency is calculated using the following equation (2) and (3)

122 respectively.

$123 \mathrm{C}\left(\mathrm{mg} / \mathrm{m}^{3}\right)=(\mathrm{A}-318.5) / 2.39$

124 Apparent removal efficiency $(\%)=\left(\mathrm{C}_{\mathrm{in}, \mathrm{p}}-\mathrm{C}_{\mathrm{out}, \mathrm{p}}\right) * 100 \% / \mathrm{C}_{\mathrm{in}, \mathrm{p}}$

125 Terminal removal efficiency $(\%)=\left(\mathrm{C}_{\text {out }, \mathrm{c}}-\mathrm{C}_{\mathrm{in}, \mathrm{c}}\right) * 100 \% / \mathrm{C}_{\mathrm{o}, \mathrm{c}}$

Where $\mathrm{A}$ is the peak area of waste concentration determined by GC, the correlation coefficient for (1) is $0.9997 ; \mathrm{C}$ is the concentration of

129 benzene series, $\mathrm{mg} / \mathrm{m}^{3} ; \mathrm{C}_{\mathrm{in}, \mathrm{p}}$ and $\mathrm{C}_{\text {out, }}$ were the inlet and outlet

130 concentration of pollutant separately; $\mathrm{C}_{\mathrm{in}, \mathrm{c}}$ and $\mathrm{C}_{\text {out }, \mathrm{c}}$ of $\mathrm{CO}_{2} ; \mathrm{C}_{\mathrm{o}, \mathrm{c}}$

131 was the total concentration of $\mathrm{CO}_{2}$ corresponding to the pollutant by complete oxidation.

To investigate the effect for $\mathrm{pH}$ and conductivity, the $\mathrm{H}_{2} \mathrm{O}_{2} \mathrm{pH}$

134 value was adjusted by adding $\mathrm{HCl}$ and $\mathrm{NaOH}$, was determined using 135 an acidimeter (Model Starter 2100/3C Pro, Shanghai Hongji 136 Instrument Co., Ltd. China), the conductivity using an 137 Conductivity Meter (DDSJ-319L, INESA SCIENTIFIC 
INSTRUMENT CO., LTD. China).

\section{Result and dicussion}

\subsection{Single effect with $\mathrm{UV}$ or $\mathrm{H}_{2} \mathrm{O}_{2}$}

\subsubsection{Apparent degradation by UV radiation}

143 Benzene was used as the target compound for this research section.

144 With the maximum power of UV radiation in our study as $30 \mathrm{~W}$, 145 Fig. 2 shows benzene is resistant under different time in which the 146 apparent degradation rate was in the range of $0.5 \%-1 \%$, there was 147 little direct UV photo-oxidation and the indirect way caused by the 148 substance in ambient air, such as $\mathrm{O}_{2}$ and $\mathrm{H}_{2} \mathrm{O}$. It is accordant with 149 the studies that toluene and benzene in air could be hardly 150 degradated under >200nm UV ligh [Zhang et al., 2003; FENG et 151 al., 2019], because $253.7 \mathrm{~nm}$ is too high to break the benzene 152 molecular bond by the photon energy at this wavelength. Although 153 dimethylbenzene could be reduced under $254 \mathrm{~nm}$ after taking a long 154 time (>3h) [Ma et al., 2007], the substance is different from benzene series. In addition, it is critical to understand the impact of reactor

156 walls on gas-phase reactivity, due to the background offgasing of

157 NOx, other reactive species and heterogeneous reactions that cause 158 “chamber radical sources" upon irradiation [Carter et al., 1982]. 
160 pollutant reduciton in our study.

161 Conditions. The experimental conditions were as follows: benzene 162 concentration, $455 \mathrm{mg} / \mathrm{m}^{3}$; gas flow, $9 \mathrm{~L} / \mathrm{min}$; reactant temperature 163 (room temperature), $25{ }^{\circ} \mathrm{C}$; UV energy, $30 \mathrm{~W}$; and residence time, $3 \mathrm{~s}$. 164

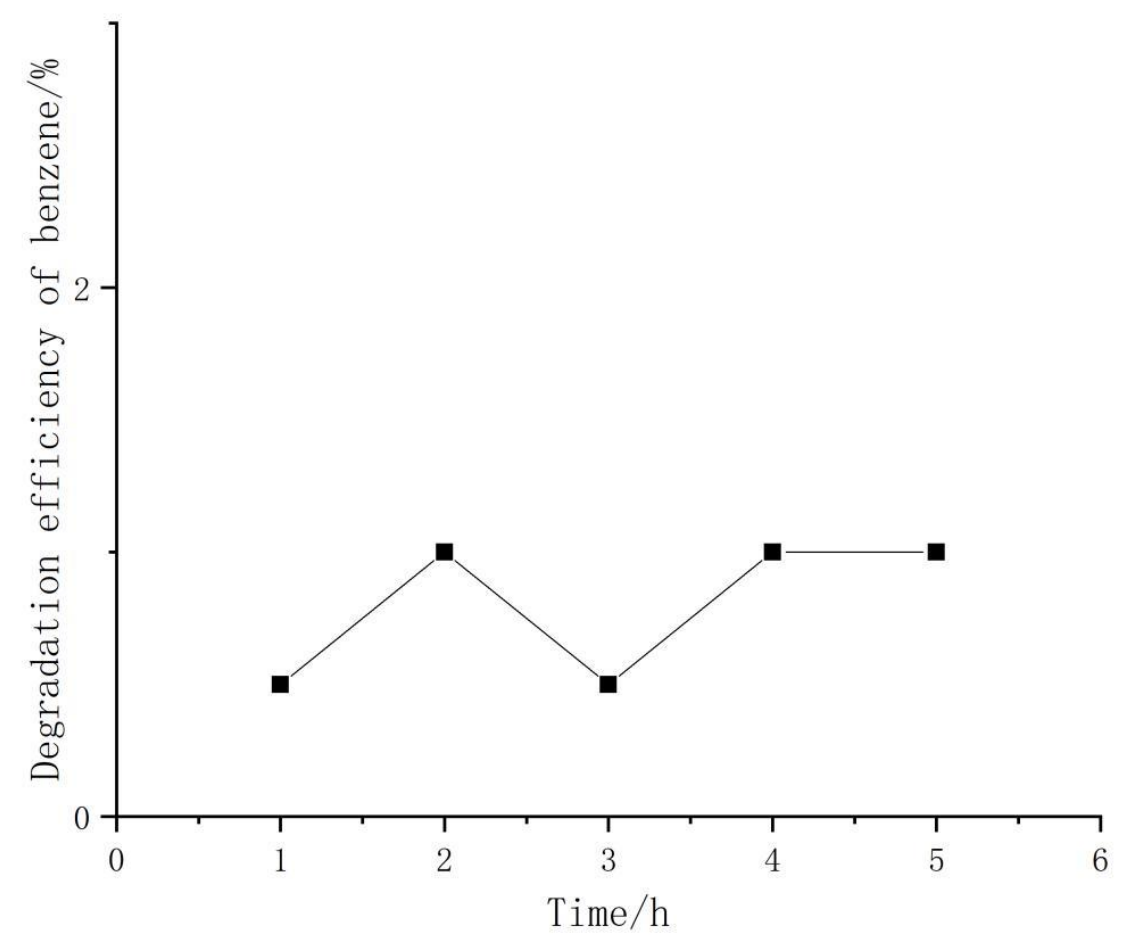
the pollutant quantity in $5 \mathrm{~h}$ reaction decreased very slightly $(\leq 1 \%)$,

171 which implied that benzene is extremely inert and difficult to be 
172 degraded by $\left[\mathrm{H}_{2} \mathrm{O}_{2}\right]_{\text {g }}$ oxidation alone. It can be deduced that the 173 oxidation capacity of $\mathrm{H}_{2} \mathrm{O}_{2}$ to benzene is very limited, and can not 174 release $\cdot \mathrm{OH}$ free radicals for the reaction without the radiation of $\mathrm{UV}$. 175 This phenomenon also proved that generating hydroxyl radicals is 176 the very necessary for GPAO. On the other hand, it was obvious that 177 the reactor was also stable under $\left[\mathrm{H}_{2} \mathrm{O}_{2}\right]_{\mathrm{g}}$ oxidation.

178 Conditions. The experimental conditions were similar to that in 3.1.1, 179 in which $4.6 \mathrm{~mol} / \mathrm{m}^{3}\left[\mathrm{H}_{2} \mathrm{O}_{2}\right]_{\mathrm{g}}$ were used to replace the UV light.

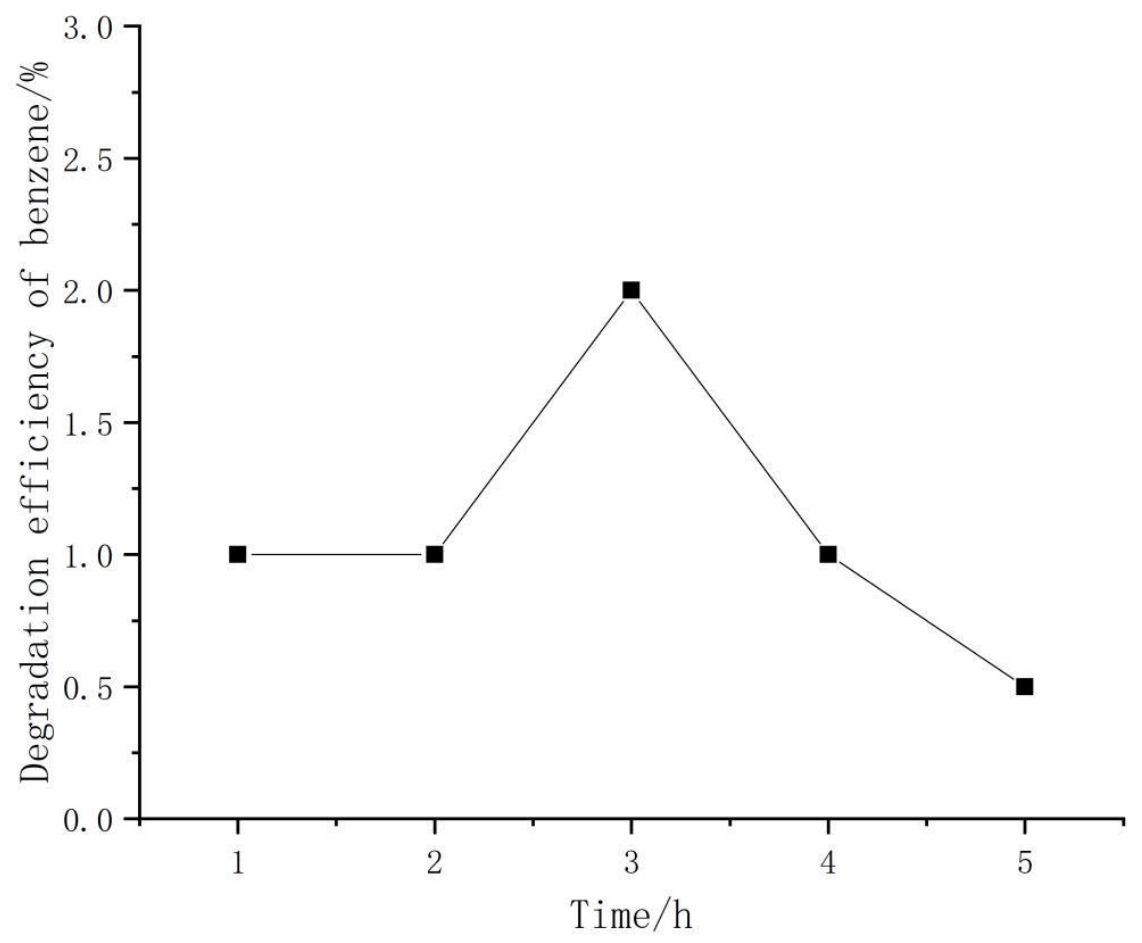
Fig. 3 apparent degradation of benzene only by $\left[\mathrm{H}_{2} \mathrm{O}_{2}\right]_{\mathrm{g}}$ 


\subsection{Apparent and terminal degradation}

185

\subsubsection{Apparent degradation by different way}

All the three treatment ways could reduce the contaminants as shown in Fig.4. Although the maximal efficiency is $31 \%$ for the toluene which lower than the related researchs [Yangxian et al., 2014; Bin et al., 2007], it is obtained in the case of very short residence time and high concentration pollutant. Thus the result was still very meaningful in which $\left[\mathrm{H}_{2} \mathrm{O}_{2}\right]_{\mathrm{g}}, \mathrm{TiO}_{2}$ and $\mathrm{ZnO}$ played the important oxidant role in the course. The fundamental role for $\mathrm{H}_{2} \mathrm{O}_{2}$ lies in the decomposing into $\bullet \mathrm{OH}$ free radicals under $\mathrm{UV}$ radiation with a certain wavelength according to the following reaction [Lee et al., 2004].

$$
\mathbf{H}_{2} \mathbf{O}_{2}+h v \stackrel{\lambda<300 \mathrm{~nm}}{\longrightarrow} 2 . \mathbf{O H}
$$

Then the degradation of pollutants could be expressed as the following equations [Bin et al., 2007]:

$$
. \mathrm{OH}+\text { Pollutant } \rightarrow \text { Intermedia te }
$$

$$
. \mathrm{OH}+\text { Intermedia te } \rightarrow \mathrm{CO}_{2}+\mathrm{H}_{2} \mathrm{O}_{2}
$$

In the other three treatment ways mixing with catalytist and PAC, the potential problem was that the $\mathrm{H}_{2} \mathrm{O}$ in $\mathrm{H}_{2} \mathrm{O}_{2}$ vapor could hinder the degradation because of its competitive adsorption onto the reaction surface with contaminants [Herrmann et al., 1999; Nazir et al., 2003]. But there were also some promotions in the progress, because 
206 the two catalysts also can produced the. $\mathrm{OH}$ radical under $253.7 \mathrm{~nm}$ 207 UV light; in addition, owing to the higher electron affinity of $\mathrm{H}_{2} \mathrm{O}_{2}$ $208(1.8 \mathrm{eV})$ than $\mathrm{O}_{2}(0.44 \mathrm{eV})$, the excited electrons on the conduction 209 band of $\mathrm{TiO}_{2}$ could be captured by $\mathrm{H}_{2} \mathrm{O}_{2}$ more easily than by $\mathrm{O}_{2}$, 210 which increased the production of $\mathrm{OH}$. For the PAC, the adsorption 211 performance could be helpful to the pollutant reduction. It is obvious 212 that the negative impacts for $\mathrm{TiO}_{2}$ and $\mathrm{PAC}$ were less than the 213 positive, and the latter treatment is better in which the huge 214 adsorption surface area has made a great contribution. For the three 215 pollutant, the desired enhanced effect for $\mathrm{ZnO}$ did not occoured, but 216 rather weakened compared with the other treaments. It was 217 concluded that $\mathrm{ZnO}$ was prone to photocorrosion [HOFFMANN et 218 al., 1995; Han et al., 1999], and its density is most highest, then the 219 shortcomings caused the instability and heterogeneity in the reaction 220 course.

221 Conditions. The experimental conditions were similar to that in 3.1.1, 222 in which $4.6 \mathrm{~mol} / \mathrm{m}^{3}\left[\mathrm{H}_{2} \mathrm{O}_{2}\right] \mathrm{g}$ was also applied. 


\section{(a)}

230

231

232

233

234

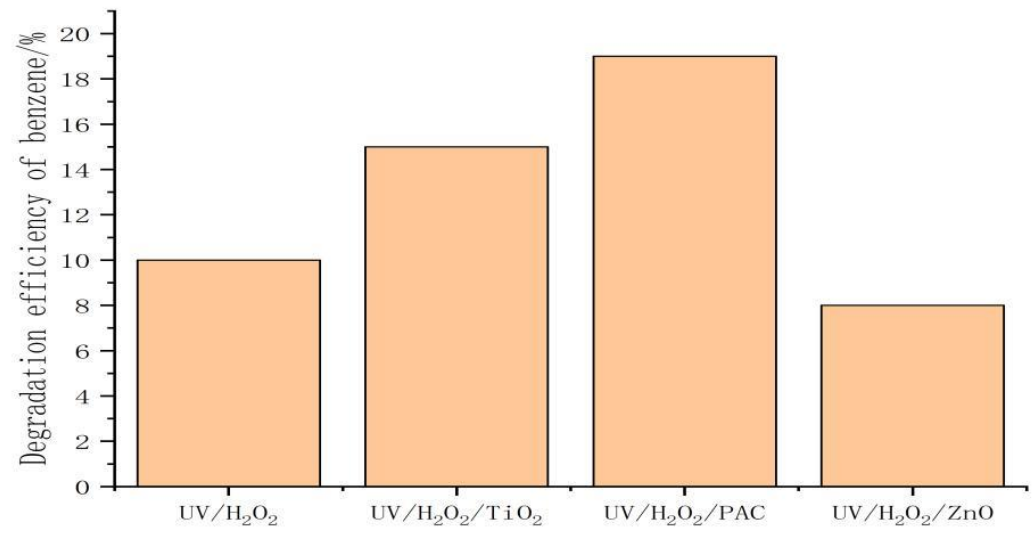

235

236

237

238

239

240

(b)

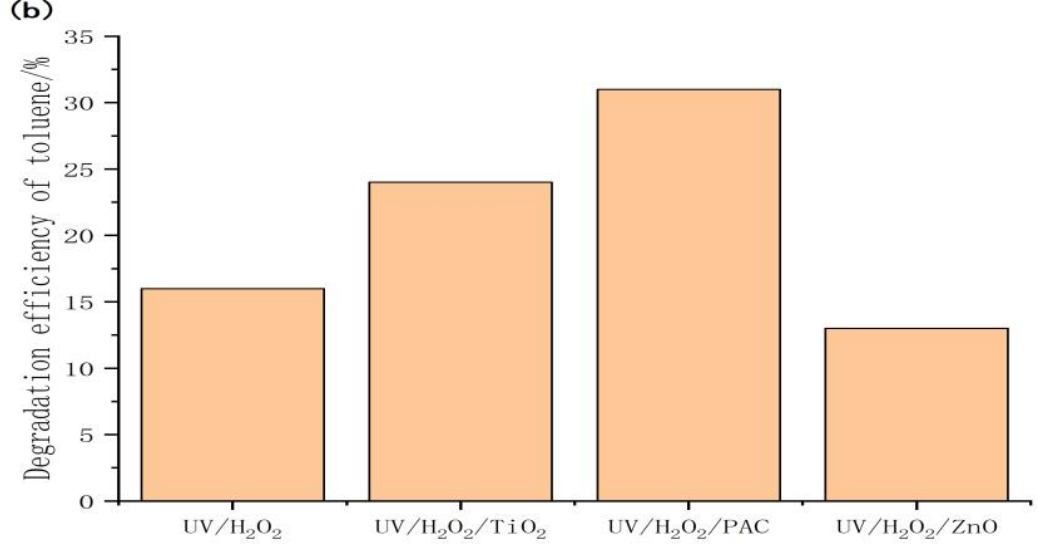

241

242

243

244

245

246

247

(C)

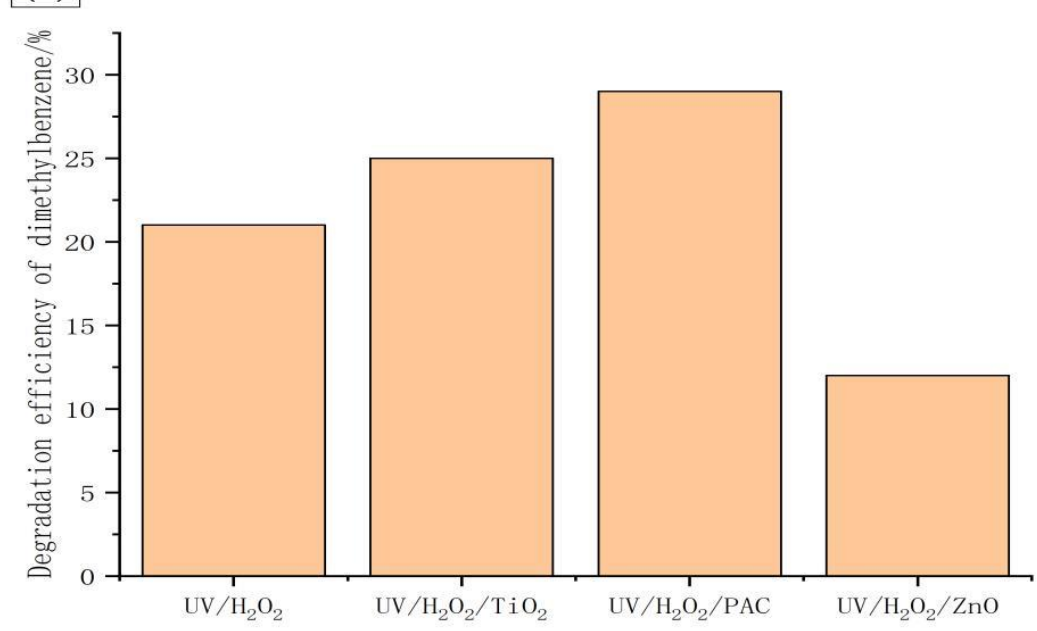

248 


\subsubsection{Terminal degradation by $\mathrm{UV} /\left[\mathrm{H}_{2} \mathrm{O}_{2}\right]_{\mathrm{g}}$}

In Fig.5, it was obvious that for both apparent and terminal rate,

254 the xylene is highest, the benzene lowest. For the toluene and xylene,

255 there are separately one and two methyl groups substituting the

256 hydrogen in benzene ring, which weaken the stability compared with

257 benzene. These exocyclic groups easily became the attacked points

258 for oxidative species, then destroyed the whole molecular structure.

259 Due to more substituting, degradation rate of xylene was most 260 remarkable.

261 The results also showed that although the apparent effects were 262 more than $10 \%$, the terminal were very low in which the maximum 263 was less than 5\%. It was denoted that most of the products were 264 intermediates, which accordant with multiful studies [Kuo-Pin et al., 2007; Matthew et al., 2014; Feng et al., 2019]. This phenomenon

266 also revealed the uncertainty for the GPAO which can not 267 compeletely removed the contaminants, hence limited the 268 application.

269 Conditions. The experimental conditions were accordant with that in $270 \quad 3.2 .1$. 


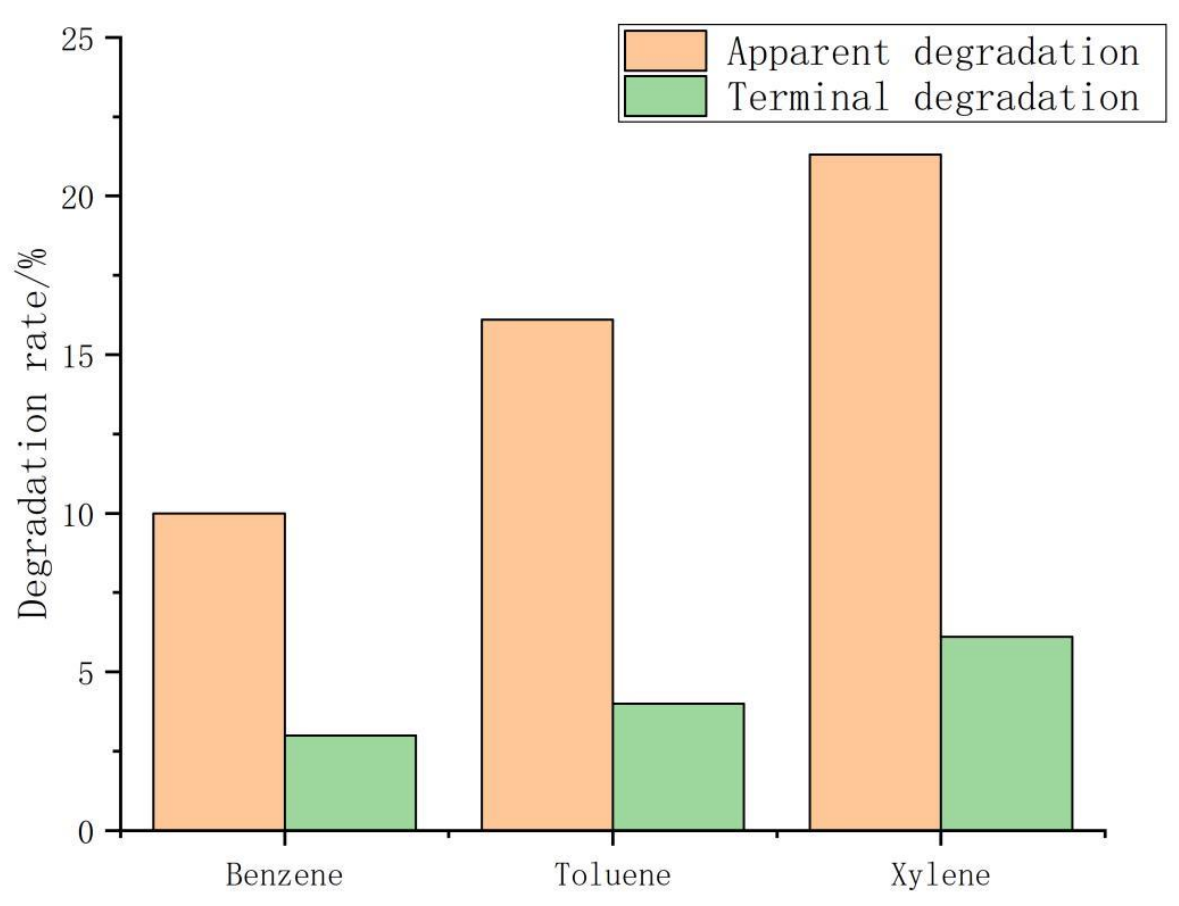

\section{$277 \quad 3.3$ characteristic absorbance}

278 Due to the multiple intermediate products in GPAO, it is meaningful

279 and necessary to focus characteristic of molecule for determining 280 whether pollutant structure were damaged. For bezene series, 281 conjugated ethylene in benzene ring plays the directive role, UV-Vis 282 was used to investigate the inlet and outlet difference for the 283 indicator. Although benzene series had B-absorption band $284(230-270 \mathrm{~nm})$ and E2 (200-210nm) respectively, the latter intensity 
285 is always higher than the former. Thus E2 was used as the the 286 maximum absorbance in our experiment, and the results are 287 mentioned in Table 1, which shows that the wavelengths value and 288 absorption intensity for toluene and xylene are higher than benzene, 289 because there were red-shift and and hyperchromic effect. It is 290 believed that the methyl groups in the two pollutants are the 291 auxochromes, their electrons in $\mathrm{n}$ orbit can produce conjugation 292 effect with them $\pi$ from the chromophores, then the electron cloud 293 can influence each other, which change the absorption intensity and 294 peak position [LI et al., 2010]. Table 1 also dispalys that there were 295 high absorbance for inlet pollutant than outlet, this phenomenon 296 proved that it is also the feasible way for determining the 297 degradation effect. In addition, although this method has clear 298 response to the conjugated ethylene in benzene ring, it is rarely used 299 in GPAO because the very few pollutant quantity in the sample 300 solution weaken the absorption peak very much; in our work, this 301 problem was solved by increasing pollutant initial concentration and 302 ending collection through longer time sampling over.

303 Conditions. The experimental conditions were accordant with that in $304 \quad 3.2 .1$. 


\begin{tabular}{llll}
\hline Pollutants & benzene & toluene & xylene \\
\hline $\begin{array}{l}\text { Characteristic } \\
\text { Wavelength }\end{array}$ & & 210.4 & 207.2 \\
$(\mathrm{~nm})$ & & \\
Absorbance of & 0.06813 & 0.0944 & 0.08744 \\
inlet pollutant & & & \\
Absorbance of 0.02290 & 0.03012 & 0.05159 \\
outlet pollutant & & \\
\hline
\end{tabular}

\subsection{Variation of conductivity}

In the similar works, conductivity was not studied as the

311 measure index, although it can indicate the special substance

312 changes after reaction. Fig. 6 shows the conductivities of inlet and

313 oulet for different pollutant degradation, in which the data slightly

314 decrease in blank test, but there are opposite effect on other 315 pollutants. The result in blank test could be explained by the fact that

316 the UV decomposition of $\mathrm{H}_{2} \mathrm{O}_{2}$ caused its ionization reduction. For

317 the latter measurement, Martina et al. found that the improvement 318 of polar products was a positive correlation with conductivity 319 [Martina et al., 1998], therefore it was believed that the 320 intermediates such as aldehyde, ketone and alcohol, were polar 
321 products accelerated by the reaction and could not be 322 completely subtracted due to the limited retention time. In addtion, 323 the increase values for benzene, xylene and toluene were 3.6, 1.2, 3240.2 respectively. This result also indicated the difference for 325 their quantity of polar intermediates, which is accordant with some 326 studies [Kislov et al., 2004; Hamilton et al., 2005; Yu et al., 1997].

327 Conditions. The experimental conditions were accordant with that in 328 3.2.1.

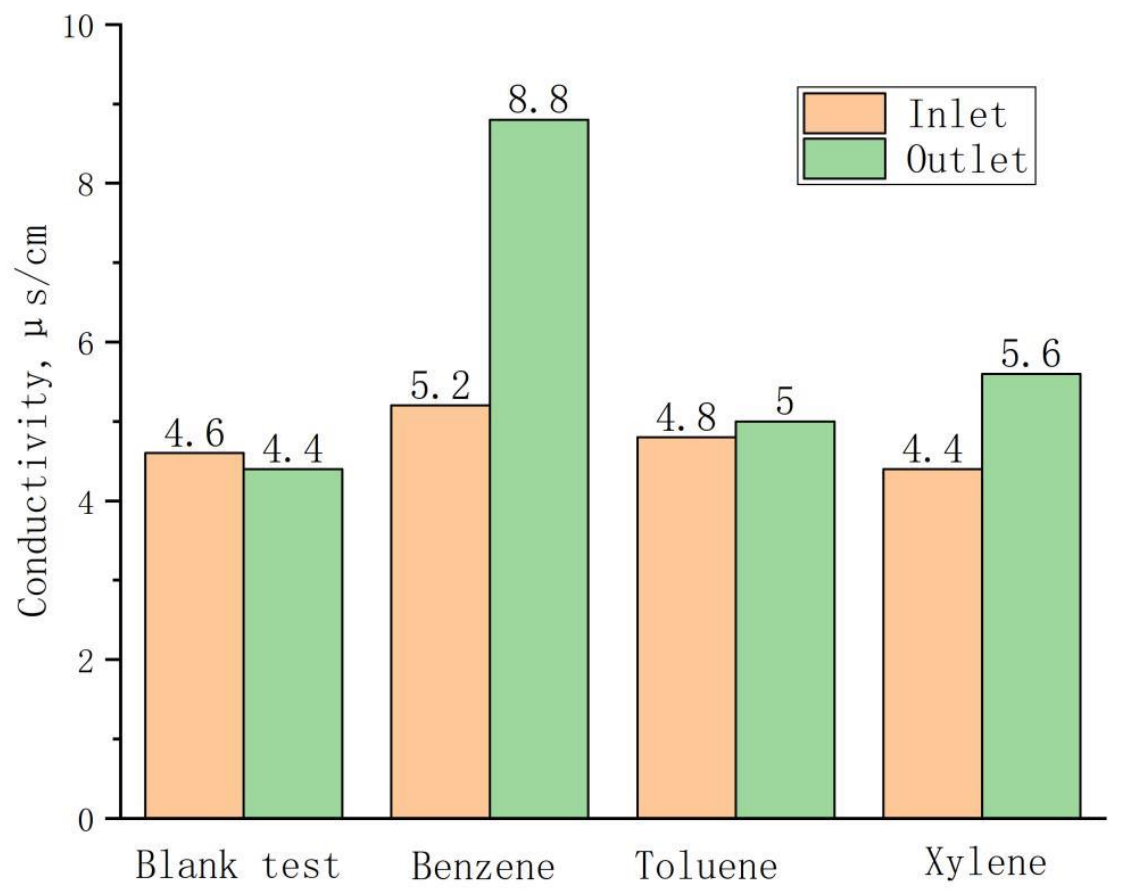




\subsection{Effect of $\mathrm{H}_{2} \mathrm{O}_{2} \mathrm{pH}$}

The benzene vapour was selected for investigated the $\mathrm{pH}$

335 influence. The effect on the waste removal efficiency is shown in Fig.

7 in which the rate decreased from 28.6 to 1.7 with the $\mathrm{H}_{2} \mathrm{O}_{2}$ solution $\mathrm{pH}$ increase 4 to 9 . It is widely recognized that $\mathrm{H}_{2} \mathrm{O}_{2}$ has stronger oxidizing property under acidic conditions, therefore the degradation was reduced with increasing the solution $\mathrm{pH}$. For the reasons, some researchs proved that $\mathrm{H}_{2} \mathrm{O}_{2}$ in solutions can produce the $\mathrm{HO}_{2}^{-}$species, which is a scavenger of $\cdot \mathrm{OH}$ radicals via the following hydrolysis reaction[Chang et al., 2008; Liu et al., 2011]. When the solution is alkaline, $\mathrm{OH}^{-}$can consume $\mathrm{H}^{+}$and accelerate $\mathrm{HO}_{2}^{-}$formation.

\section{$\mathrm{H}_{2} \mathrm{O}_{2} \leftrightarrow \mathrm{HO}_{2}^{-}+\mathbf{H}^{+}$}

$\mathrm{HO}_{2}{ }^{-}+\bullet \mathrm{OH} \rightarrow \mathrm{H}_{2} \mathrm{O}+\mathrm{O}_{2}^{-}$

Besides, the $\mathrm{OH}^{-}$can also consume $\cdot \mathrm{OH}$ radicals through the following reaction [Zehavi and Rabani; 1971], thereby reducing the removal effiency of benzene

$349 \mathrm{OH}^{-}+\bullet \mathbf{O H} \rightarrow \mathrm{H}_{2} \mathrm{O}+\mathrm{O}_{2}^{-}$

350 Conditions. Except for $\mathrm{pH}$, the other experimental conditions were 351 accordant with that in 3.2.1. 


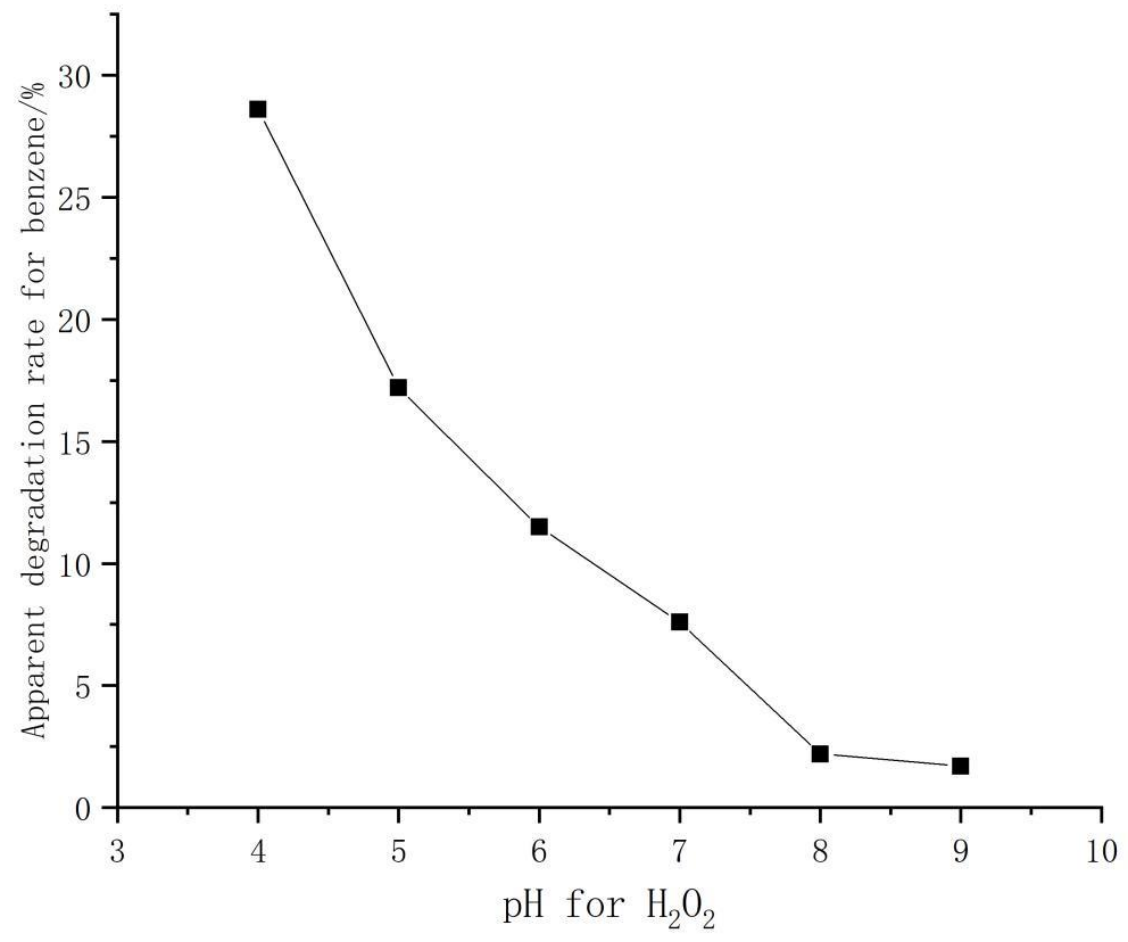

354

Fig.7 Effect of $\mathrm{H}_{2} \mathrm{O}_{2} \mathrm{pH}$ for benzene degradation

\subsection{Apparent degradation by different UV power}

The influence of UV radiation has been investigated by the different UV power of $10 \mathrm{~W}, 20 \mathrm{~W}, 30 \mathrm{~W}, 40 \mathrm{~W}$ and $50 \mathrm{~W}$, in which the apparent degradation rate of benzene were $6 \%, 10 \%, 17 \%, 19 \%$, 19\% respectively, as shown in the fig. 8. The results display that the degradation effect increase with raising the UV power at the value from $10 \mathrm{~W}$ to $40 \mathrm{~W}$, in which the improvement between $30 \mathrm{~W}$ and $40 \mathrm{~W}$ was slighter than the former and no progress from $40 \mathrm{~W}$ to $50 \mathrm{~W}$. It could be deduced that the. $\mathrm{OH}$ concentration were increased 
366 by increasing the UV intensity, thus the chain reactions were 367 strengthen to obtain a higher reactant consumption rate [Tadic et al., 368 2002]. However, when the UV radiated power exceeds a certain 369 value, several side reactions (reaction 10-13) also simultaneously 370 occured in the system, resulting in the self-loss of $\cdot \mathrm{OH}$. Thus, with 371 further increases in the light power of $40 \mathrm{~W}$, the pollutant removal 372 efficiency only increased slightly, then not change in $50 \mathrm{~W}$ which 373 was the equilibrium state of opposite action.

$$
\mathrm{H}_{2} \mathrm{O}_{2}+\bullet \mathrm{OH} \rightarrow \mathrm{HO}_{2} \bullet+\mathrm{H}_{2} \mathrm{O}
$$

$\bullet \mathrm{OH}+\bullet \mathrm{OH} \rightarrow \mathrm{H}_{2} \mathrm{O}_{2}$

$\mathrm{HO}_{2} \bullet+\mathrm{HO}_{2} \bullet \rightarrow \mathrm{H}_{2} \mathrm{O}_{2}+\mathrm{O}_{2}$

$\bullet \mathrm{OH}+\mathrm{HO}_{2} \bullet \rightarrow \mathrm{H}_{2} \mathrm{O}+\mathrm{O}_{2}$

376 Conditions. Except for UV light intensity, the other experimental conditions were accordant with that in 3.2.1. 


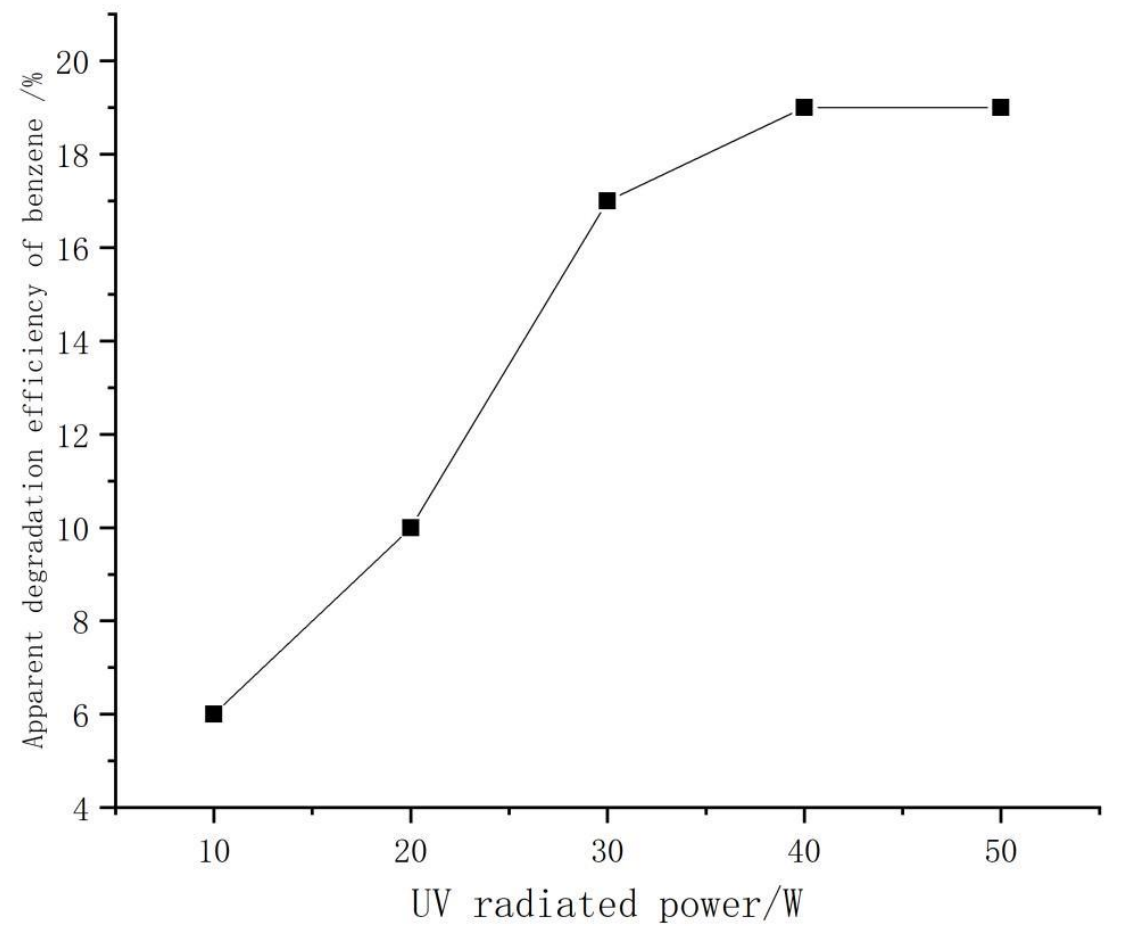

Fig. 8 Influence of UV power for benzene degradation

\subsection{Effect of initial benzene concentration}

Under the same condition of reaction, benzene was used to study the effect of pollutant concentration from 248 to $756 \mathrm{mg} / \mathrm{m}^{3}$ in the experiments. The results are shown in Fig. 9, in which the degradation efficiency decreased when the initial concentration of benzene is increased. For a single chemical reaction system, by the general theory, increasing reactant concentration is able to raise the rate. But for the photochemical reaction in which improving degradation required more oxidants for degradation, elevating 
392 induced more and more impermeable to UV radiation which cause 393 the .OH can only be irradiated by a smaller portion of UV light to 394 form lower free radicals [Aleboyeh et al., 2005], thus the rate 395 decreased.

396

397

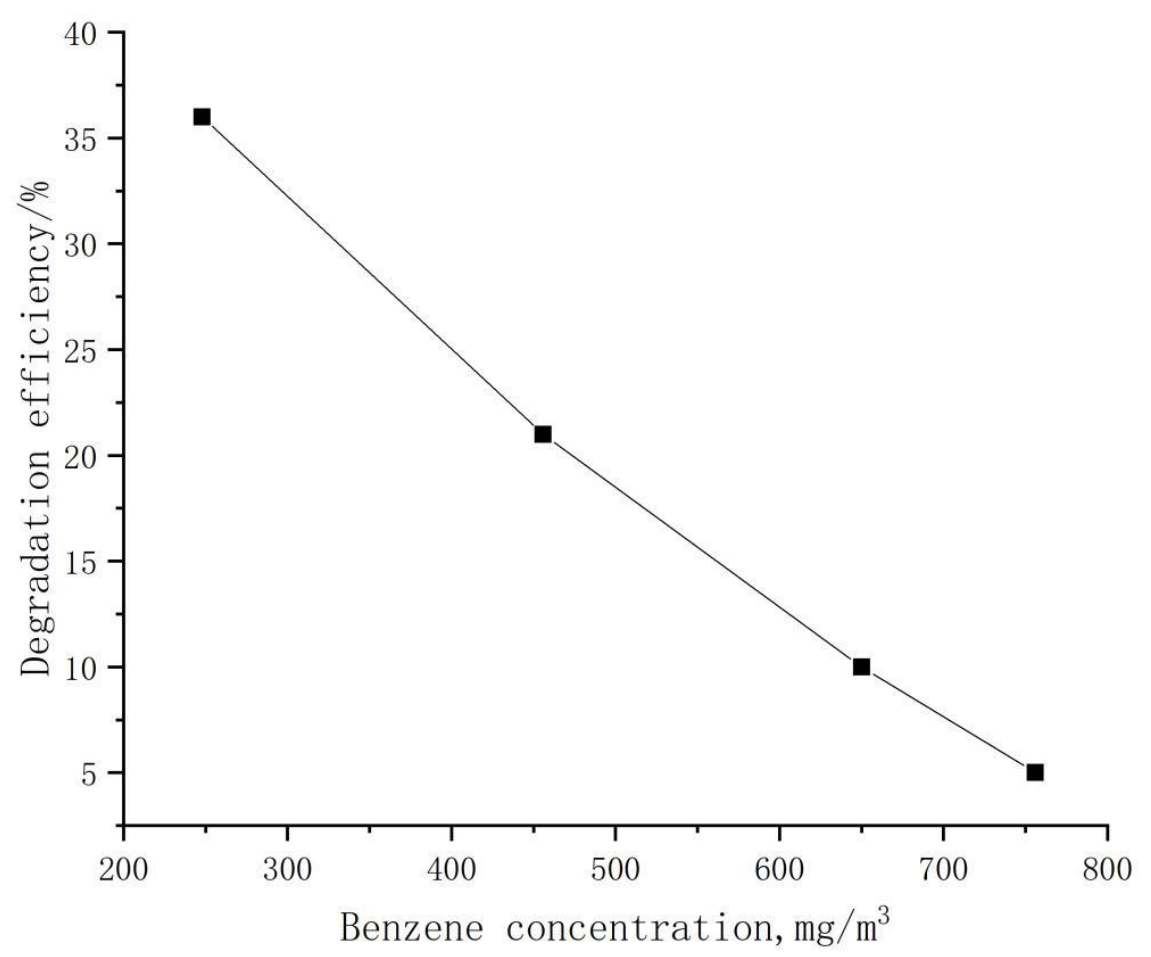

Fig. 9 Influence of concentration for benzene degradation

400

401 Conditions. Except for pollutant concentration, the other 402 experimental conditions were accordant with that in 3.2.1. 403 404 
The reaction system including the reactor made of FEP film, $\left[\mathrm{H}_{2} \mathrm{O}_{2}\right]_{\mathrm{g}}$ as oxidant with UV light, was stable in the study, could also remarkably removal benzene series. For the present work, the reaction

409 condition are unfavorable compared with the related, especially to shorter residence time and higher pollutant concentration, thus it is expected that with the increase of reaction time, satisfied efficiency can be obtained. In

412 addition, it was very important to ensure the stability of $\mathrm{H}_{2} \mathrm{O}_{2}$, pollution 413 load and light transmittance, therefore enhancing the power of UV-light, 414 reducing the $\mathrm{pH}$ of $\mathrm{H}_{2} \mathrm{O}_{2}$ and pollutant concentration could improve the 415 treatment effect in our experiment. In the GPAO course, although the 416 characteristic structure of benzene series can be destroyed, there were 417 multiple intermediate polar products, which cause the apparent 418 degradation rate was much higher than the terminal. Thus it is necessary 419 to further reserach for completely removing the waste.

\section{${ }_{420}$ Acknowledgments}

421 The authors would like to thank the surport by Zhongshan Science 422 and Technology Project (2019B2015) during the practical part of this 423 work.

424 -Ethical Approval: Not applicable. 
-Consent to Participate: Not applicable.

-Consent to Publish: Not applicable.

-Authors Contributions:Yuping JIANG analyzed and interpreted the experiment and data of present study, was a major contributor in writing the manuscript; Juanjuan SONG review the content of the article; Andong ZHU prepared the instrucment for the experiment. All authors read and approved the final manuscript.

-Funding: This work was supported by the Zhongshan Science and Technology Project (2019B2015).

-Competing Interests:The authors declare that they have no competing interests.

-Availability of data and materials: All data generated or analysed during this study are included in this published article.

\section{Reference}

Alapi, T. , Craeynest, K. V. , Langenhoeve, H. V. , Dewulf, J. , Dombi, A., 2007. Direct vuv photolysis of chlorinated methanes and their mixtures in a nitrogen stream. Chemosphere, 66(1), $139-144$.

Aleboyeh, A., Moussa, Y., Aleboyeh, H., 2005. The effect of operational parameters on $\mathrm{UV} / \mathrm{H}_{2} \mathrm{O}_{2}$ decolourisation of acid blue 
Anglada, J.M., Aplincourt, P., Bofill, J.M., Cremer, D., 2002. Atmospheric formation of $\mathrm{OH}$ radicals and $\mathrm{H}_{2} \mathrm{O}_{2}$ from alkene ozonolysis under humid conditions. Chem.Phys. Chem., 2, $215-221$.

Anastasio, C. , Faust, B. C. , Rao, C. J. , 1997. Aromatic carbonyl compounds as aqueous-phase photochemical sources of hydrogen peroxide in acidic sulfate aerosols, fogs, and clouds. 1 . non-phenolic methoxybenzaldehydes

and methoxyacetophenones with reductants (phenols). Environmental Science Technology, 31(1), 218-232.

Bernstein, J. A. , Alexis, N. , Bacchus, H. , Bernstein, I. L. , Fritz, P. , Horner, E. , 2008. The health effects of non-industrial indoor air pollution. Journal of Allergy \& Clinical Immunology, 121(3), $585-591$.

Carter, W. P. L. , Atkinson, R. , Winer, A. M. , Jr, J. N. P. , 1982. Experimental investigation of chamber-dependent radical sources. International Journal of Chemical Kinetics, 14(10), 1071-1103.

Choudhary, V. R. , Jana, P., 2007. In situ generation of hydrogen peroxide from reaction of $\mathrm{O}_{2}$ with hydroxylamine from hydroxylammonium salt in neutral aqueous or non-aqueous 
medium using reusable $\quad \mathrm{Pd} / \mathrm{Al}_{2} \mathrm{O}_{3} \quad$ catalyst. Catalysis Communications, 8(11), 1578-1582.

470 Dehne, Clarck, G. , 1997. Alan d. mcnaught and andrew wilkinson, compilers.compendium of chemical terminology, iupac recommendations. Terminology, 4(2), 347-351(5).

Hamilton, J. F. , Webb, P. J. , Lewis, A. C. , Reviejo, M. M. , 2005. Quantifying small molecules in secondary organic aerosol formed during the photo-oxidation of toluene with hydroxyl radicals. Atmospheric Environment, 39(38), 7263-7275.

Han, Z., Zhao, H., 1999. Progress in Applied Research of the Heterogeneous Photocatalysis on Semiconductors [J]. PROGRESS IN CHEMISTRY, 1999,11(1): 1-10.

Hein, M. , Henning, H. , Isengard, H. D. , 1998. Determination of total polar parts with new methods for the quality survey of frying fats and oils. Talanta, 47(2), 447.

Herrmann, J. M. , Matos, J. , Disdier, J. , Guillard, C. , Blanco, J., 1999. Solar photocatalytic degradation of 4-chlorophenol using the synergistic effect between titania and activated carbon in aqueous suspension. Catalysis Today, 54(2), 255-265.

Hoffmann, M. R. , Martin, S. T. , Choi, W. , Bahnemann, D. W., 1995. Environmental applications of semiconductor photocatalysis. Chemical Reviews, 95(1), 69-96. 
490 Fang, G.D., Zhou, D.M., Dionysiou, D.D., 2013.Superoxide mediated production ofhydroxyl radicals by magnetite nanoparticles: demonstration in the degradation of 2-chlorobiphenyl. J. Hazard. Mater.250e251, $68 \mathrm{e} 75$.

French, G.L; Otter, J.A; Shannon, K.P; Adams, N.M.T., Watling, D., Parks, M.J., 2004. Tackling contamination of the hospital environment by methicillin-resistant staphylococcus aureus (mrsa): a comparison between conventional terminal cleaning and hydrogen peroxide vapour decontamination sciencedirect. Journal of Hospital Infection, 57( 1), 31-37.

Gerd, S., Rodolfo J. B., Detlef, B., Alberto, E. C., 2003. Photocatalytic reactors for treating water pollution with solar illumination. ii: a simplified analysis for flow reactors. Chemical Engineering Science.58(12), 2601-2615.

Javier, Marugán., Hufschmidt, D. , María-José López-Muñoz., Selzer, V. , Bahnemann, D., 2006. Photonic efficiency for methanol photooxidation and hydroxyl radical generation on silica-supported $\mathrm{TiO} 2$ photocatalysts. Applied Catalysis B Environmental, 62(3-4), 201-207.

Johnson, M. S. , Nilsson, E. J. K. , Svensson, E. A. , Langer, S., 2014. Gas-phase advanced oxidation for effective, efficient in situ control of pollution. Environmental Science and 
513 Jovan M. Tadić, Ivan O. Juranić, Moortgat, G. K., 2001. 514 Photooxidation of $n$-heptanal in air: norrish type $i$ and ii processes and quantum yield total pressure dependency. Journal of the Chemical Society Perkin Transactions, 2, 2(1), 135-140.

Jörg, Wohlgemuth., Dagmar, Pfäfflin., Jaeschke, W. , Deutsch, F. ,

518 Hoffmann, P. , Ortner, H. M. , 2001. Photochemical formation of 
Absorption Parameters of Dissolved Organic Matter Extracted from Chicken Manure during Composting. Spectroscopy \& Spectral Analysis, 30(11):3081-3085.

Liu, H., Bruton, T.A., Li, W., Buren, J.V., Sedlak, D.L., 2016. Oxidation of Benzene by Persulfate in the Presence of Fe(III)and $\mathrm{Mn}(\mathrm{IV})$-Containing Oxides: Stoichiometric Efficiency and Transformation Products. Environmental Science \& Technology, 50(2):890-898.

Liu, Y., Zhang, J., Sheng, C., 2011. Study on the kinetics of no removal from simulated flue gas by a wet ultraviolet $/ \mathrm{H}_{2} \mathrm{O}_{2}$ advanced oxidation process. Energy Fuels, 25(MAR.-APR.), $1547-1552$.

MA, G., YIN, Y., WANG, S., 2007. Degradation of xylene in gas phase by ozone and UV light. Journal of Shandong jianzhu university, 22(1):57-60.

Mase, K. , Yoneda, M. , Yamada, Y. , Fukuzumi, S. , (2016). Seawater usable for production and consumption of hydrogen peroxide as a solar fuel. Nature Communications, 7, 11470-11477.

Meng-Wen, Chang., Chia-Chun, Chung., 2010. Dye decomposition kinetics by $\mathrm{UV} / \mathrm{H}_{2} \mathrm{O}_{2}$ : initial rate analysis by effective kinetic modelling methodology. Chemical

Engineering 
557

558

559

560

561

562

563

564

565

566

567

568

569

570

571

572

573

574

575

576

577

Mo, J., Zhang, Y. , Xu, Q. , Lamson, J. J. , Zhao, R., 2009. Photocatalytic purification of volatile organic compounds in indoor air: a literature review. Atmospheric Environment, 43(14), 2229-2246.

Moeller, D. , 2009. Atmospheric hydrogen peroxide: evidence for aqueous-phase formation from a historic perspective and a one-year measurement campaign. Atmospheric Environment, 43(37), 5923-5936.

Muruganandham, M., Swaminathan, M., 2004. Photochemical oxidation of reactive azo dye with $\mathrm{UV}-\mathrm{H}_{2} \mathrm{O}_{2}$ process. Dyes \& Pigments, 62(3), 269-275.

Nazir, M. , Takasaki, J. , Kumazawa, H. , 2003. Photocatalytic degradation of gaseous ammonia and trichloroethylene over $\mathrm{TiO}_{2}$ ultrafine powders deposited on activated carbon particles. Chemical Engineering Communications, 190(3), 322-333.

Tojima, S., Tobita, S., Shizuka, H., 1999.Electron transfer from triplett 1.4-dimethoxybenzen to hydronium ion in aqueous solution. J. Phys. Chem. A 103, 6097-6105.

Wang, J. H. , Ray, M. B., 2000. Application of ultraviolet photooxidation to remove organic pollutants in the gas 
phase. Separation \& Purification Technology, 19(1-2), 11-20.

Xu, B. , Gao, N. Y. , Sun, X. F. , Xia, S. J. , Rui, M. , Simonnot, M.

Yu, K. P., Lee, G. W. M., 2007. Decomposition of gas-phase toluene by the combination of ozone and photocatalytic oxidation process $\left(\mathrm{TiO}_{2} / \mathrm{UV}, \mathrm{TiO}_{2} / \mathrm{UV} / \mathrm{O}_{3}\right.$, and $\left.\mathrm{UV} / \mathrm{O}_{3}\right)$. Applied Catalysis B Environmental, 75(1-2), 29-38.

Yu, J., Jeffries, H. E., Sexton, K. G., 1997. Atmospheric photooxidation of alkylbenzenes-i. carbonyl product analyses. Atmospheric Environment, 31(15), 2261-2280.

Zhang, L., Anderson, W. A., 2013. Kinetic analysis of the photochemical decomposition of gas-phase chlorobenzene in a uv reactor: quantum yield and photonic efficiency. Chemical 
601 Zhang, P., Liang, F., Chen, Q., Yu, G., Zhu, W., 2003. photocatalytic 602 degradation of low level toluene in the gas phase. Huanjing $603 \quad$ Kexue, 24(6), 54-58.

604 Zheng, J., Shao, M., Che, W., Zhang, L., Zhong, L., Zhang, Y., 2009. 605 Speciated voc emission inventory and spatial patterns of ozone 606 formation potential in the pearl river delta, china. Environmental $607 \quad$ Science \& Technology, 43(22), 8580-8586.

608 Zhuangzhuang, F., Mingqiang, H., Jun, X. U., Shunyou, C., 609 Weixiong, Z., Changjin, H. U., 2019. Experimental study of the 610 secondary organic aerosol formed from the aqueous 611 photooxidation of benzene. Acta Scientiae Circumstantiae, 39 (7) : 2362-2368.

613 Zehavi, D., Rabani, J., 1971. Pulse radiolytic investigation of $\mathrm{O}_{a q}{ }^{-}$ 614 radical ions. J. Phys. Chem. 1971， 75: 1738-1744. 
Figures

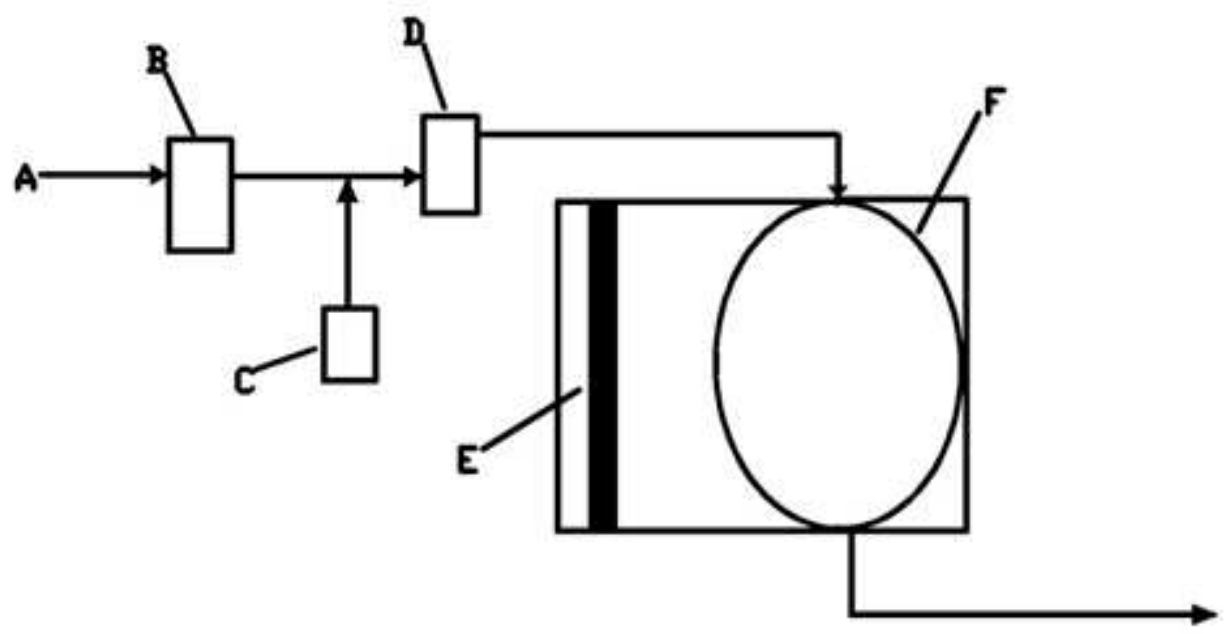

Figure 1

Schematic of experimental system. Legend: A, Air; B, liquid pollutant vessel; C, H2O2 solution vessel; D, gas mixing tank; E, UV lamp囚253.7nm®; F, FEP bag.

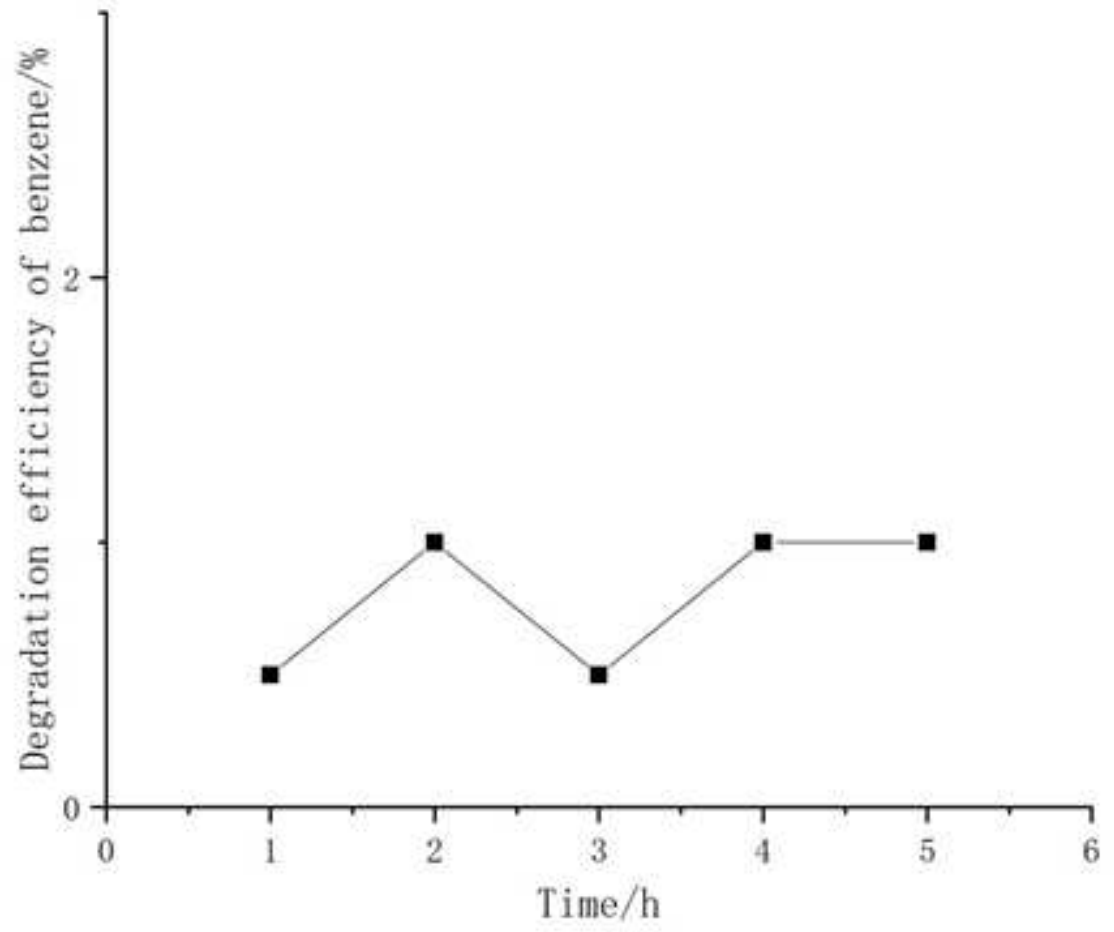

Figure 2

apparent degradation of benzene only by UV radiation 


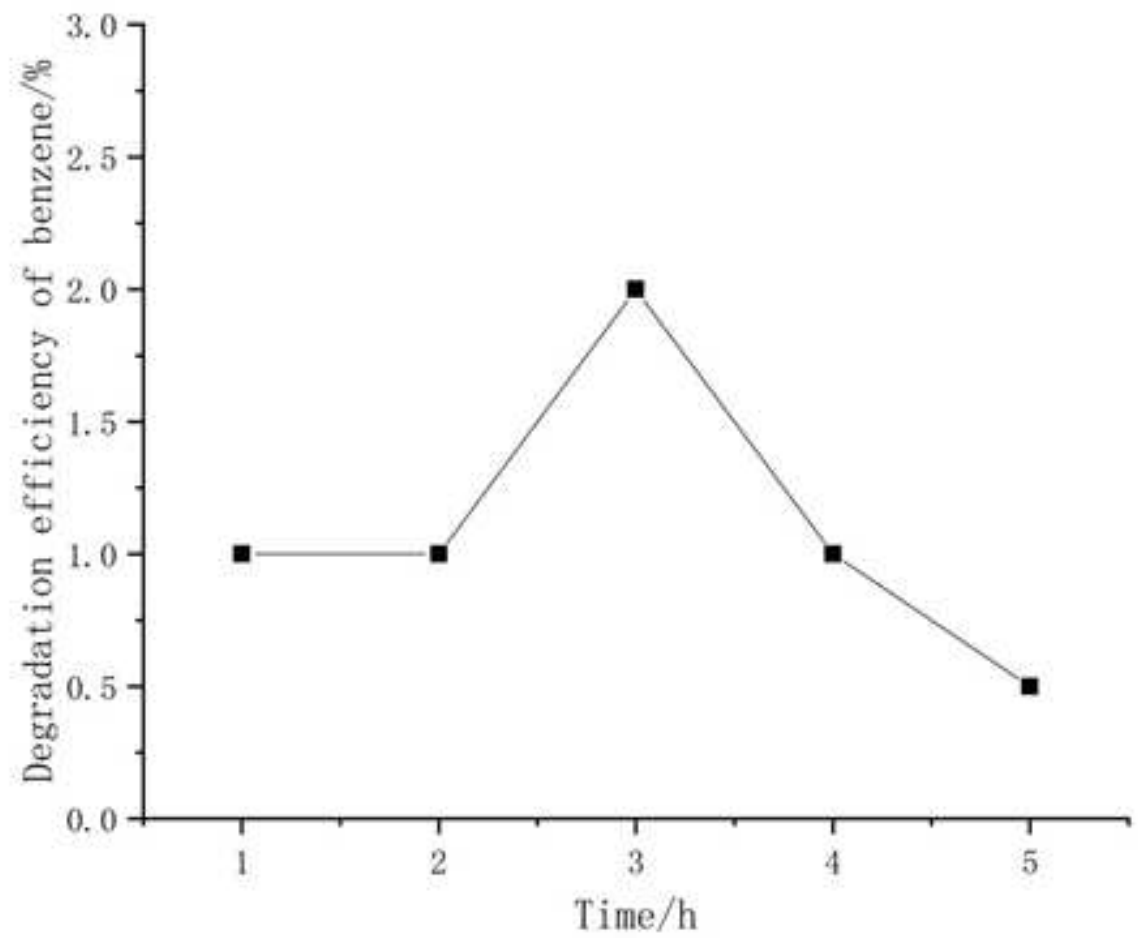

Figure 3

apparent degradation of benzene only by [H2O2]g 

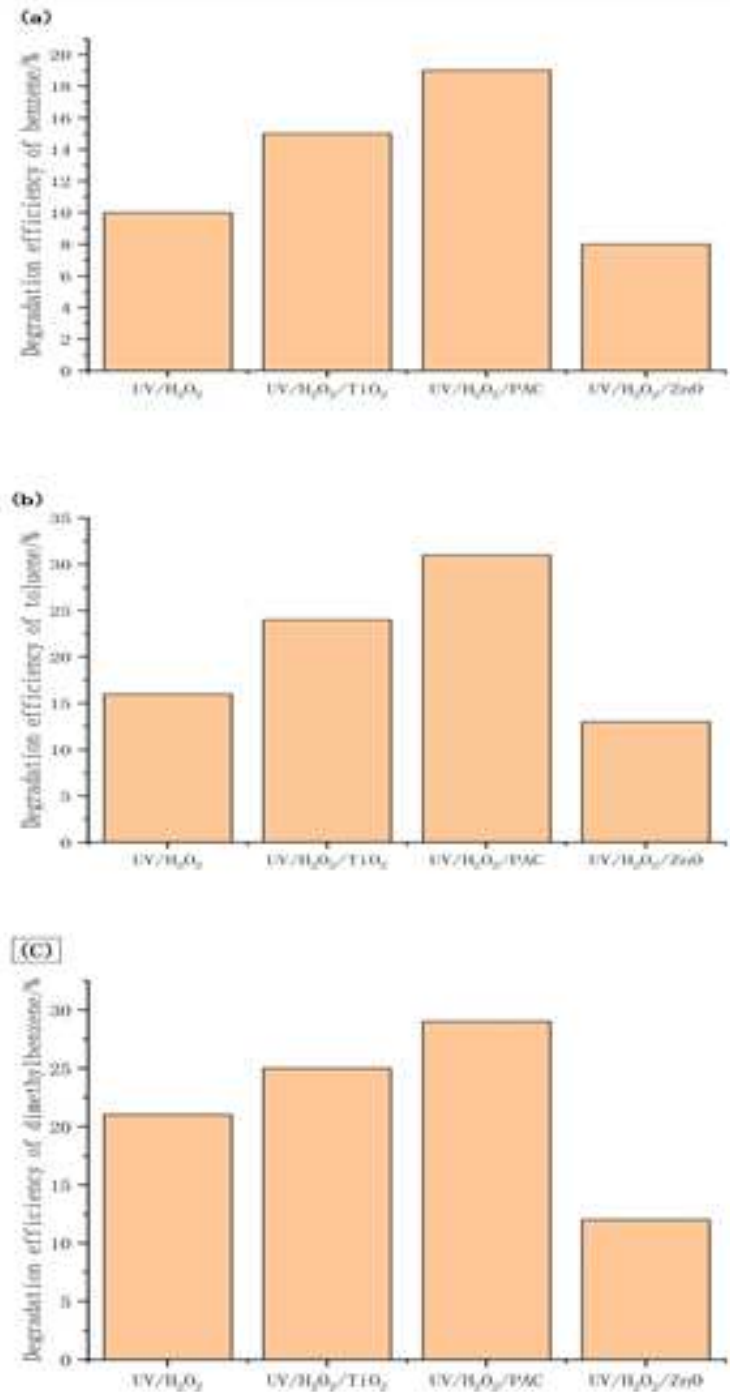

Figure 4

Apparent degradation rate by different ways with $\mathrm{H} 2 \mathrm{O} 2$ 


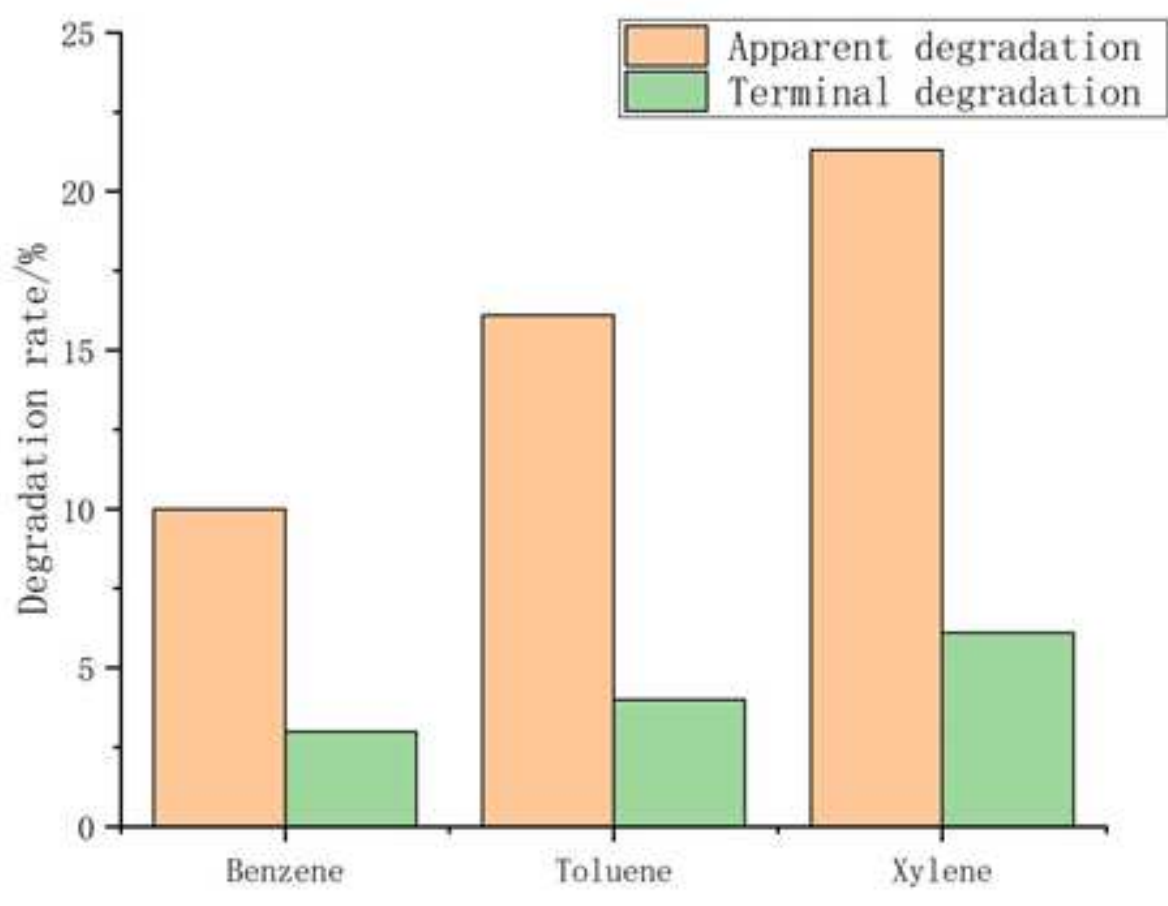

Figure 5

Comparison between terminal and apparent degradation

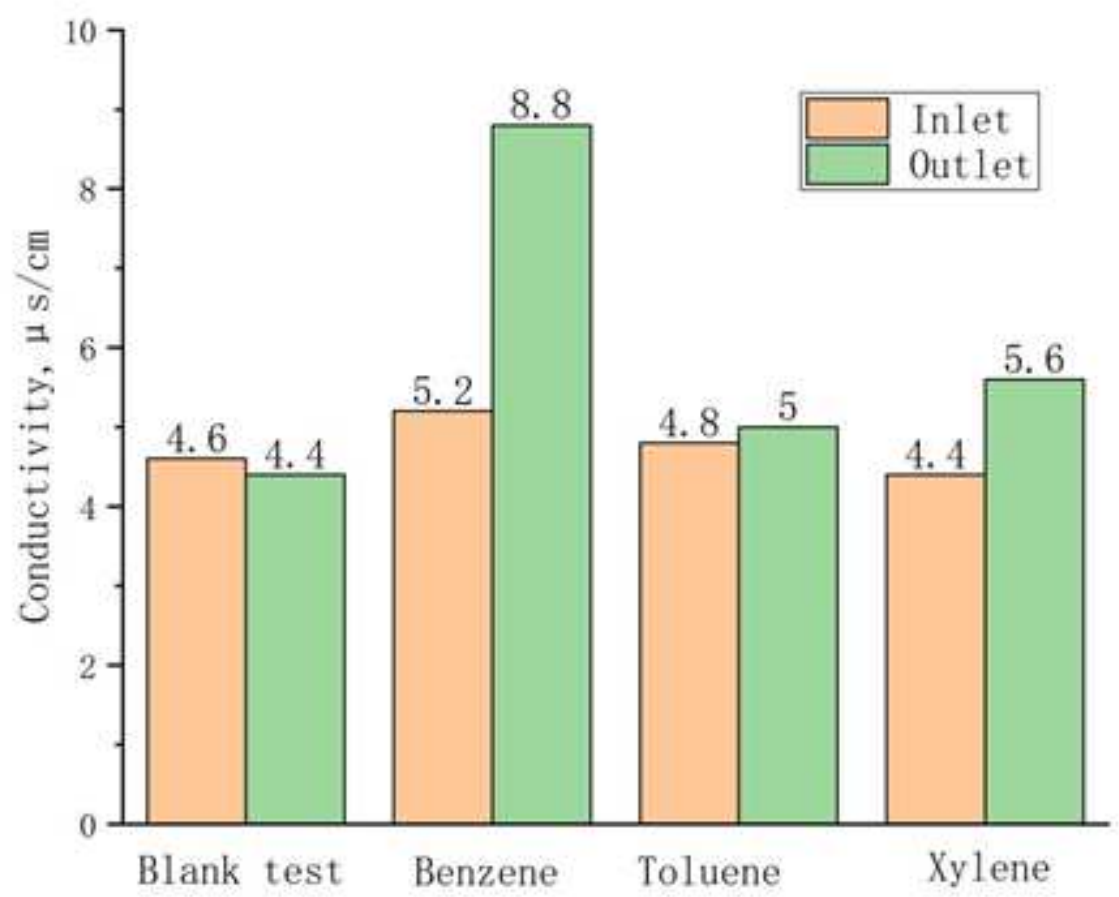

Figure 6

Variation of conductivity for different pollutant degradation 


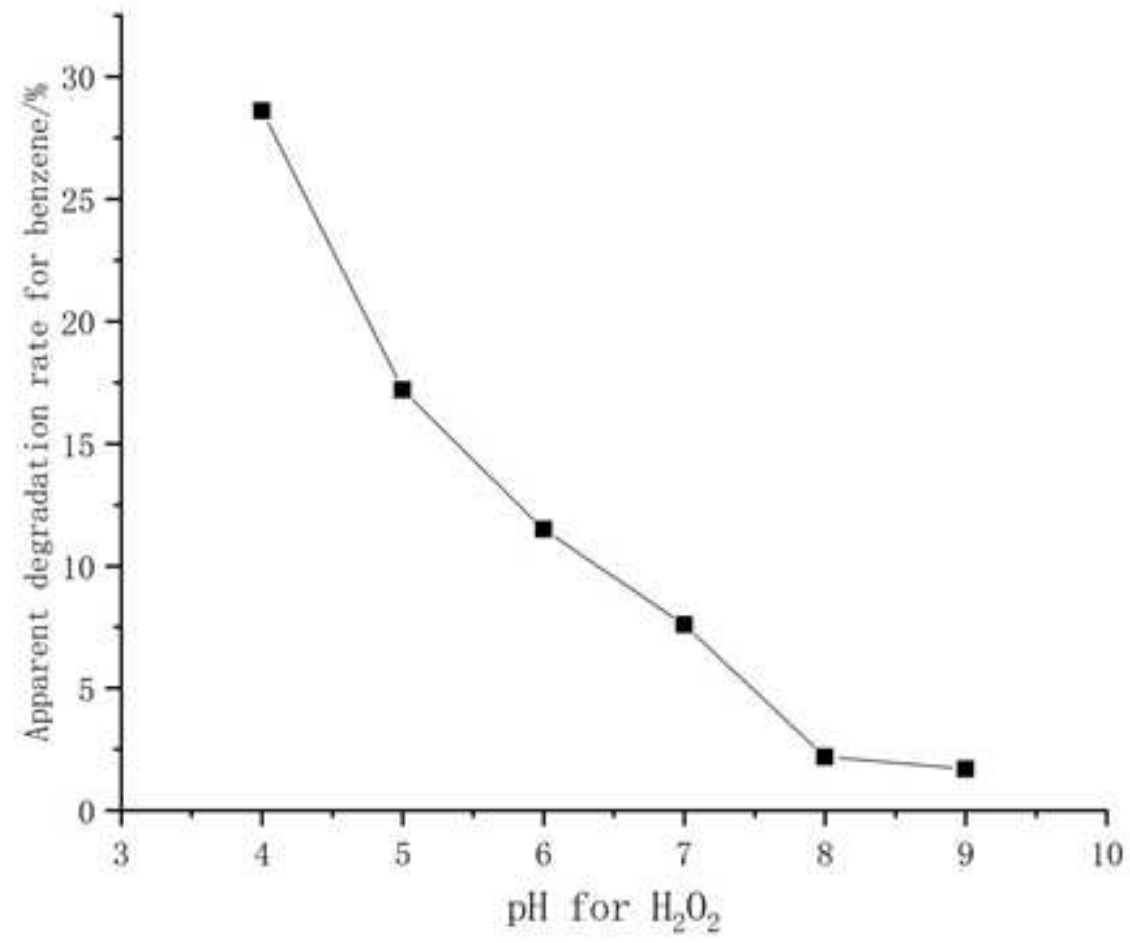

Figure 7

Effect of $\mathrm{H} 2 \mathrm{O} 2 \mathrm{pH}$ for benzene degradation

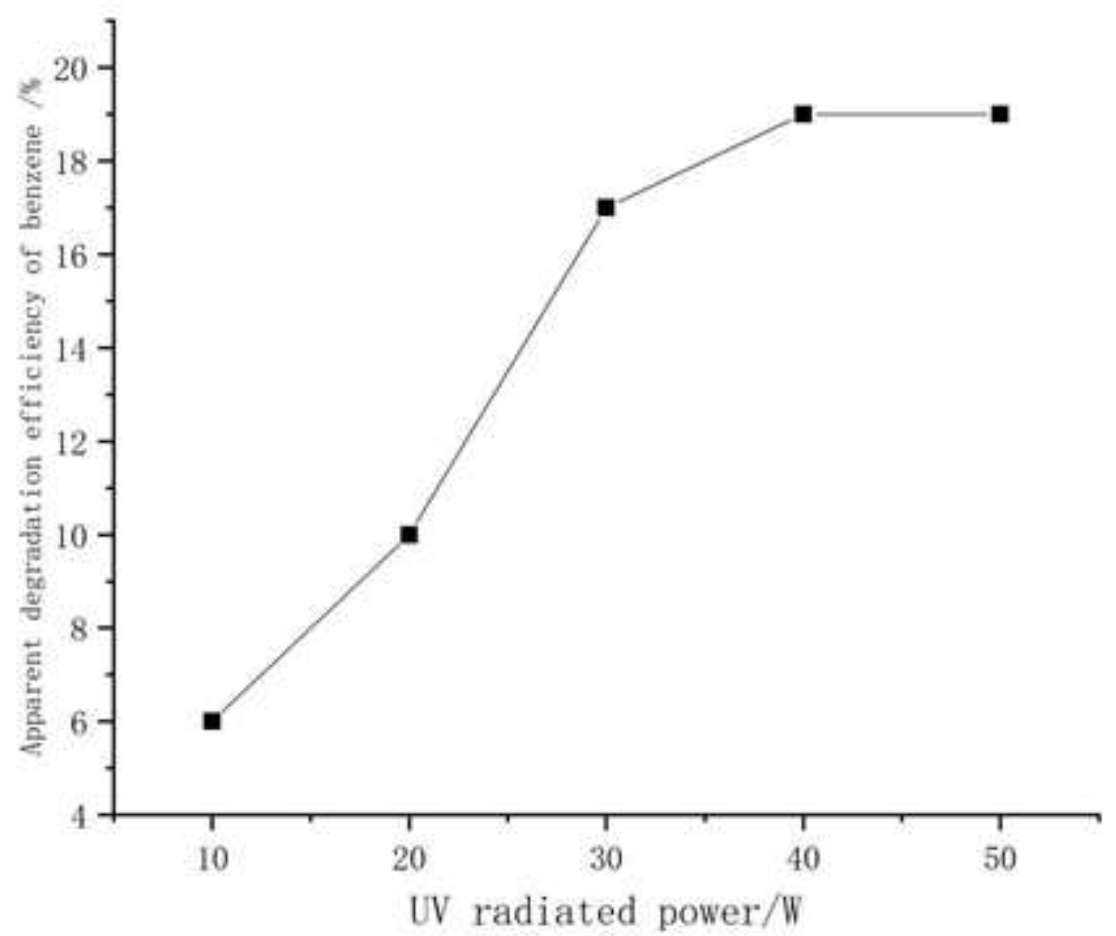

Figure 8 
Influence of UV power for benzene degradation

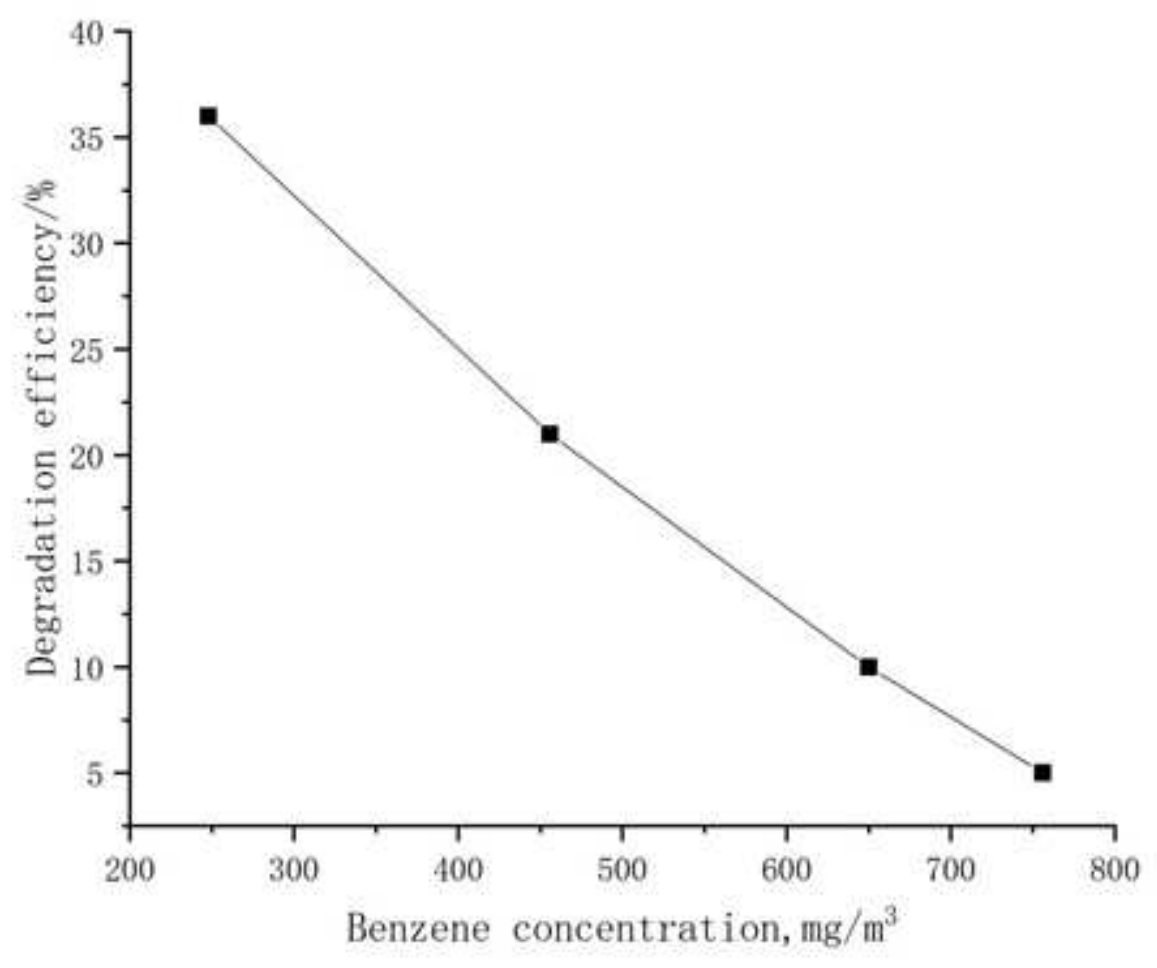

Figure 9

Influence of concentration for benzene degradation 